\title{
Extracranial saccular atherosclerotic aneurysm of the internal carotid artery (ICA) treated by an oblique end-to-end primary anastomosis
}

\author{
Jakub Kaczynski, ${ }^{1}$ Maria Wilczynska, ${ }^{2}$ Marek Blaszczynski, ${ }^{3}$ Louis Fligelstone $^{4}$
}

${ }^{1}$ Radiology Department, Cardiff and Vale University Health Board, Cardiff, UK

${ }^{2}$ General Medicine Department, Hywel Dda Health Board,

Llanelli, UK

${ }^{3}$ Vascular Surgery Department, Hywel Dda Health Board, Carmarthen, UK

${ }^{4}$ Vascular Surgery Department, ABM University Health Board, Swansea, UK

\section{Correspondence to} Jakub Kaczynski,

jakub.kaczynski@hotmail.co.uk
To cite: Kaczynski J, Wilczynska M, Blaszczynski M, et al. BMJ Case Reports Published online: [please include Day Month Yearl doi:10.1136/ bcr-2012-007705

\section{DESCRIPTION}

A 67-year-old woman presented with a 3-month history of a pulsatile mass on the right side of the neck and a hoarse voice. She did not report any neurological symptoms, and there was no history of trauma, infection or any previous surgical intervention. There was no medical history and the patient was a non-smoker. Physical examination revealed a pulsatile mass below the right angle of mandible with some discomfort along the mandible. CT angiogram (CTA) showed an elongated and tortuous internal carotid artery (ICA) with $180^{\circ}$ bend before the formation of $2.7 \mathrm{~cm}$ saccular (anteroposterior diameter) aneurysm (figure 1). Subsequently, a total aneurysmectomy with end-to-end oblique anastomosis under a general anaesthesia was performed (figure 2). Overall the patient made an uneventful postoperative recovery. Histopathology confirmed the presence of a true atherosclerotic saccular aneurysm with no evidence of vasculitis or active inflammation (figure 3 ).

Aneurysms of the extracranial portion of carotid arteries are rare. Their reported incidence is about $0.8-1 \%$, and they comprise less than $5 \%$ of all peripheral aneurysms. ${ }^{1-3}$ In the older group of patients, atherosclerosis remains the commonest aetiology. ${ }^{2}$ However, in younger patients causes such as trauma, fibromuscular dysplasia, mycobacterial infection, vasculitis and dissection have been described. ${ }^{24-6}$

Symptoms depend on the aneurysm's size, location, aetiology and can be divided into three main categories. Compression can present as dysphagia, hoarseness or Horner's syndrome ${ }^{2}{ }^{7-10}$ In the presented case, hoarseness was caused by the combination of pressure effect and stretching of the vagus

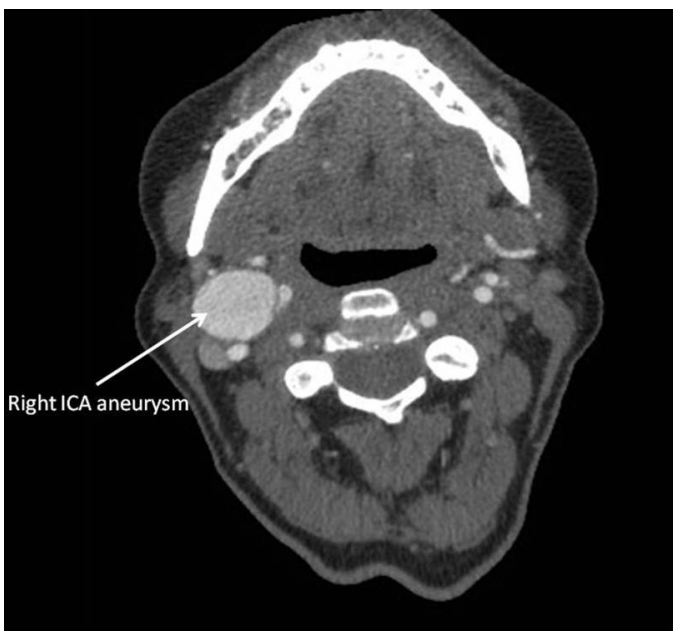

Figure 1 Right internal carotid artery aneurysm. nerve with the recurrent laryngeal nerve (figure 4). The discomfort along the mandible was thought to be associated with the pressure on the cervical branch of the facial nerve. Ruptures with haemorrhage have been reported, but predominantly with mycotic aneurysms. ${ }^{4}{ }^{6}$ However, the most serious consequences of ICA aneurysms are related to the high risk of thromboembolic events resulting in stroke or transient ischaemic attack ${ }^{1} \cdot{ }^{11}$ Diagnosis is usually established by a combination of clinical and radiological findings. Radiological confirmation can be achieved by Duplex ultrasound scan (US), Digital Subtraction Angiography (DSA), MRI and MR or CTA. ${ }^{45}$

Conservative management involving anticoagulant therapy has been found to be ineffective, primarily due to $50 \%$ stroke rate. ${ }^{11}$ Therefore, surgical approach remains the first line treatment and is advised even in the asymptomatic patients. ${ }^{3} 5$ The most frequently advocated surgical approach involves an aneurysmectomy with either direct end-to-end anastomosis or interposition graft (prosthetic or vein). ${ }^{3}$ Saccular aneurysms have been found to be associated with elongation of ICA, which can be useful in vascular reconstruction. ${ }^{11}$ Similarly, in this case careful dissection demonstrated elongated and

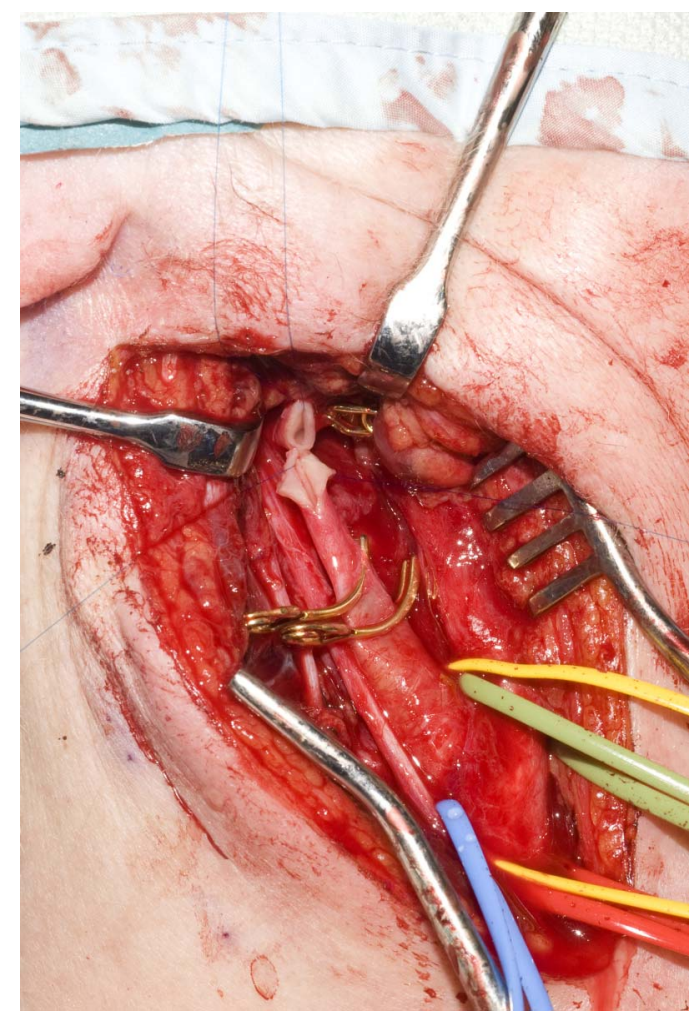

Figure 2 End to end oblique primary anastomosis. 


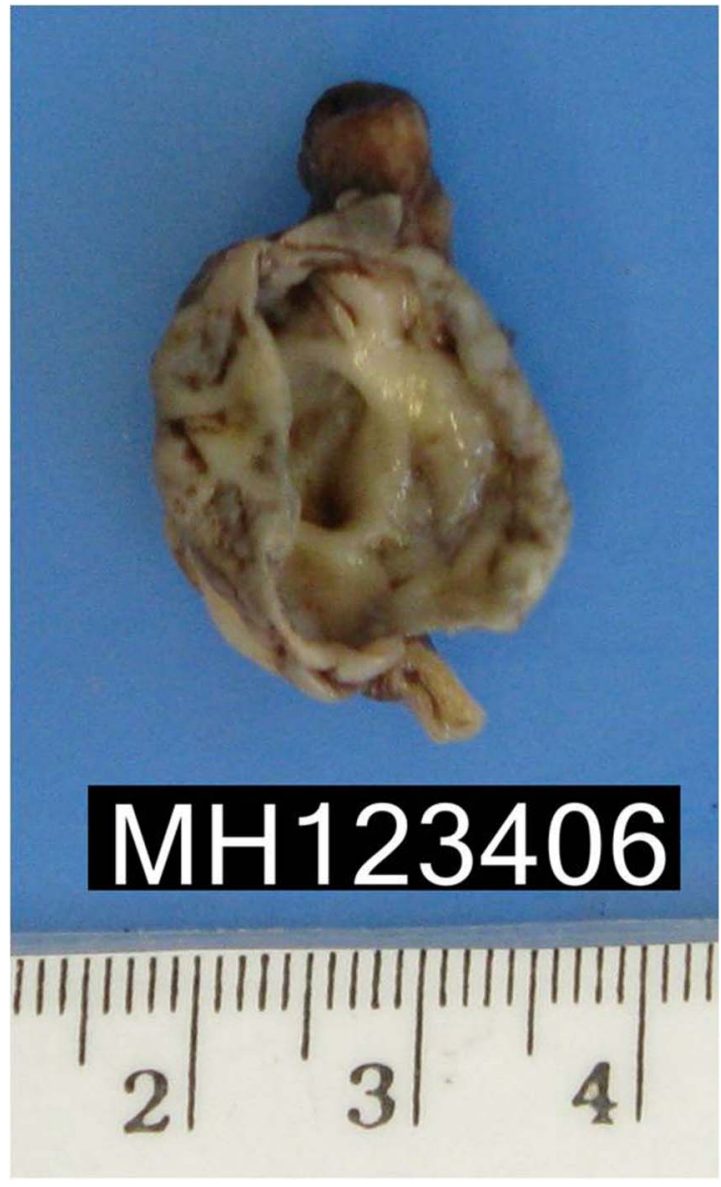

Figure 3 Saccular atherosclerotic internal carotid artery aneurysm.

torturous ICA with $180^{\circ}$ bend (figure 4). This allowed for the resection of the redundant portion of the ICA and end-to-end primary anastomosis (figure 2). Upon opening of the aneurism's sac, the cerebral perfusion was maintained by the Pruitt Inahara carotid shunt (figure 5). Interestingly, the use of shunt in such circumstances remains controversial, with reported use ranging from $3 \%$ to $67 \% .^{11-13}$ Some authors suggest insertion of one of the shunt tubes into the proximal common carotid artery (CCA) via separate arteriotomy instead of the proximal portion of ICA. ${ }^{11}$ In order to reduce the risk of embolisation and to shorten the shunt

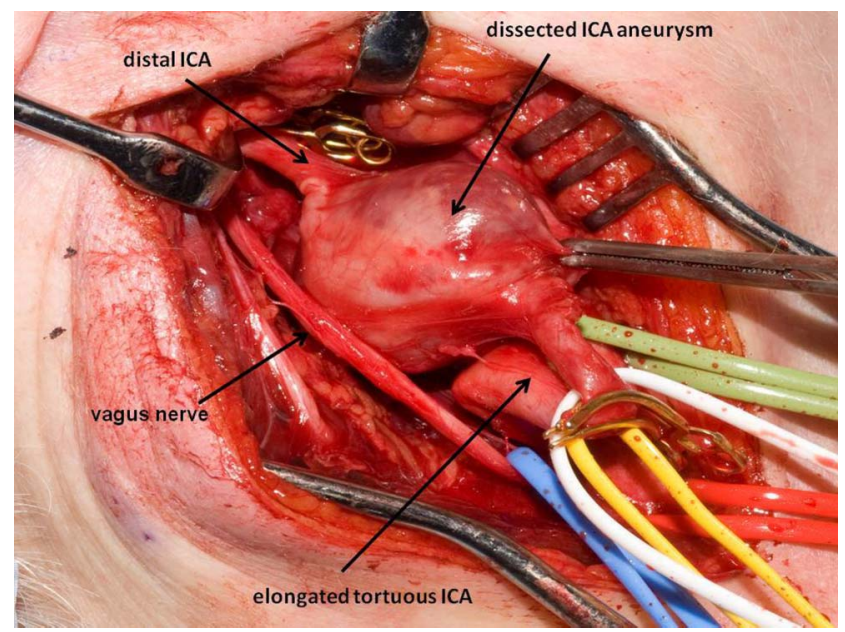

Figure 4 Stretched vagus nerve and elongated, torturous internal carotid artery.

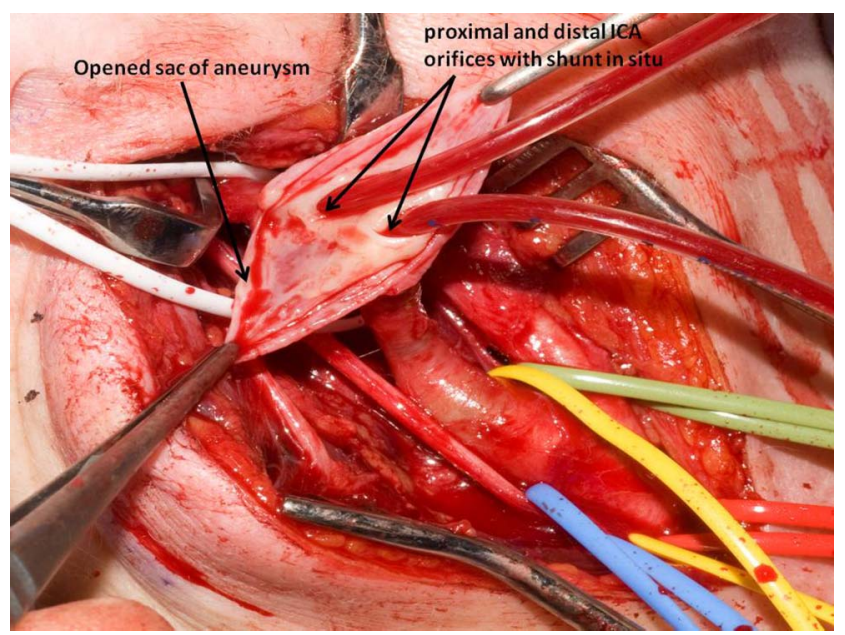

Figure 5 Shunt within the opened sac of the internal carotid artery aneursym.

time a preoperative Duplex US was performed, which confirmed patency and lack of thrombus. In addition, a standard dose of 3500 units of intravenous heparin was administered during the operation with $3 \mathrm{~min}$ of circulation time. In a view of above, cannulation of the ICA at both proximal and distal orifices was achieved with no complications. Following resection of the aneurysm, an end-to-end oblique anastomosis of ICA was performed. Hand held Doppler confirmed triphasic signals in CCA, external carotid artery and ICA.

Unfortunately, treatment of the aneurysms located at distal portions of the ICA and at the base of the skull is not feasible with standard surgical approach. ${ }^{7} 91415$ In such circumstances, endovascular procedures with the use of covered stents offer a promising alternative. ${ }^{11} 1617$ Endovascular approach avoids dissection of the sac, which is often adjacent to main neural structures. ${ }^{16}$ Present evidence shows satisfactory patency rates with no reported cases of cranial nerves damage or stent migration. ${ }^{11}$ However, endoluminal manipulation is associated with the risk of spreading the thrombus ${ }^{516}$ and presence of the stent is subsequently associated with the reduced flexibility during patient's head movements. Also, the presence of the stent in the distal portions of ICA makes impossible to offer any form of surgical treatment in a case of complications after endovascular procedure. ${ }^{5}{ }^{16}$ Although, endovascular treatment may be applicable in selected cases, one must remember that current and limited data make it impossible to draw definitive conclusions. ${ }^{5}$ Therefore, at present open surgery remains the choice of treatment of the extracranial aneurysms of ICA. ${ }^{5} 16$

\section{Learning points}

- Symptoms of the internal carotid artery (ICA) aneurysm depend on the aneurysm's size, location and aetiology.

- Due to a high rate of thromboembolic complications, even asymptomatic patients should undergo treatment.

- Open surgical approach is currently the gold standard in the management of extracranial ICA aneurysms.

\section{Competing interests None.}

Patient consent Obtained.

Provenance and peer review Not commissioned; externally peer reviewed. 


\section{REFERENCES}

1 El-Sabrout R, Cooley DA. Extracranial carotid artery aneurysms: Texas Heart Institute experience. J Vasc Surg 2000;31:702-12.

2 Mishwani AH, Haleem A, Kiani KA. Giant aneurysm of the extracranial internal carotid artery. J Coll Physicians Surg Pak 2010;20:345-6.

3 Ilic N, Koncar I, Dragas $M$, et al. Aneurysm of the kinked extracranial internal carotid artery: extraordinary union. Am Surg 2010;76:E214-15.

4 O'Connell JB, Darcy S, Reil T. Extracranial internal carotid artery mycotic aneurysm: case report and review. Vasc Endovascular Surg 2009:43:410-15.

5 Biasi L, Azzarone M, De Troia A, et al. Extracranial internal carotid artery aneurysms: case report of a saccular wide-necked aneurysm and review of the literature. Acta Biomed 2008;79:217-22.

6 Angle N, Dorafshar AH, Ahn SS. Mycotic aneurysm of the internal carotid artery-a case report. Vasc Endovascular Surg 2003;37:213-17.

7 Wilding LJ, Howlett DC, Anderson HJ, et al. Extracranial internal carotid artery aneurysm presenting as symptomatic hypoglossal and glossopharyngeal nerve paralysis. J Laryngol Otol 2004;118:150-2.

8 Vasileiadis I, Kapetanakis S, Fiska A, et al. A giant aneurysm of the internal carotid artery, which caused dysphagia: case study and short review of literature. Folia Morphol 2010;69:267-70.

9 Lane RJ, Weisman RA, Savino PJ, et al. Aneurysm of the internal carotid artery at the base of the skull: an unusual cause of cranial neuropathies. Otolaryngol Head Neck Surg 1980;88:230-2.
10 Oruckaptan $\mathrm{HH}, \mathrm{Ozcan} \mathrm{OE}$. Giant extracranial internal carotid artery aneurysm: a rare presentation with an oropharyngeal mass. Otolaryngol Head Neck Surg 2001;125:571-3.

11 Hosoda K, Fujita S, Kawaguchi T, et al. The use of an external-internal shunt in the treatment of extracranial internal carotid artery saccular aneurysms: technical case report. Surg Neurol 1999;52:153-5.

12 Chittithavorn V, Rergkliang C, Chetpaophan A, et al. Repair of extra-cranial internal carotid artery aneurysm with application of modified carotid shunt: a case report. J Med Assoc Thai 2005;88:530-3.

13 Troisi N, Dorigo W, Pulli R, et al. A case of traumatic internal carotid artery aneurysm secondary to carotid shunting. J Vasc Surg 2010;51:225-7.

14 Ktenidis K, Lioupis A, Megalopoulos A, et al. New exposure technique for management of giant internal carotid artery aneurysm. J Vasc Surg 2011:54:522-5.

15 Pennell C, Westfall S. Multidisciplinary approach to the management of an extracranial internal carotid artery aneurysm approaching the base of the skull in a young patient. Ann Vasc Surg 2011;25:699 e5-8.

16 Juszkat R, Wrobel M, Golusinski W, et al. Stent-graft treatment of extracranial internal carotid artery aneurysm. Eur Arch Otorhinolaryngol 2005;262:826-9.

17 Trinidad-Hernandez M, Introcaso JH, White JV. Combined open and endovascular treatment of a saccular aneurysm and redundant loop of the internal carotid artery. J Vasc Surg 2006;44:642-6.

Copyright 2013 BMJ Publishing Group. All rights reserved. For permission to reuse any of this content visit http://group.bmj.com/group/rights-licensing/permissions.

BMJ Case Report Fellows may re-use this article for personal use and teaching without any further permission.

Become a Fellow of BMJ Case Reports today and you can:

- Submit as many cases as you like

- Enjoy fast sympathetic peer review and rapid publication of accepted articles

- Access all the published articles

- Re-use any of the published material for personal use and teaching without further permission

For information on Institutional Fellowships contact consortiasales@bmjgroup.com

Visit casereports.bmj.com for more articles like this and to become a Fellow 